\title{
Life in turbulent flows: interactions between hydrodynamics and aquatic organisms in rivers
}

Trinci, G., Harvey G. L., Henshaw, A. J., Bertoldi, W. and Hölker, F.

Journal: WIREs Water (accepted for publication February 2017)

Article type: Advanced Review

Abstract

The turbulent properties of flow in rivers are of fundamental importance to aquatic organisms yet are rarely quantified during routine river habitat assessment surveys or the design of restoration schemes due to their complex nature. In this paper, we review the two-way interactions between aquatic biota and hydrodynamics in rivers, and key methodological approaches used in their quantification, to encourage more explicit consideration of the importance of turbulence in river science and management. We explore recent advances and issues relating to the study of these interactions in the field, laboratory and numerical modelling, the use of artificial and live biota, and different flow measurement technologies. We also review methods for the quantification of ecologically-relevant turbulent flow properties, identifying key descriptors of the intensity, periodicity, orientation and scale of turbulent flow structures. Our analysis highlights not only the various ways in which plants and animals modify the flow field but also how this can deliver beneficial effects relating to solute exchange, food availability, oxygenation, waste removal, locomotion and predator-prey interactions. It also demonstrates potential threats to growth and survival relating to turbulence, including injury, dislodgement, increased energy expenditure, mortality and complex influences on predators and prey. We conclude by identifying some remaining barriers to the integration of turbulence into the science and practice of river assessment and restoration but also opportunities in the form of controlled laboratory experimentation, increasingly sophisticated flow sensors and imaging technologies, and numerical simulation of turbulence that could advance understanding in this complex field of research. 


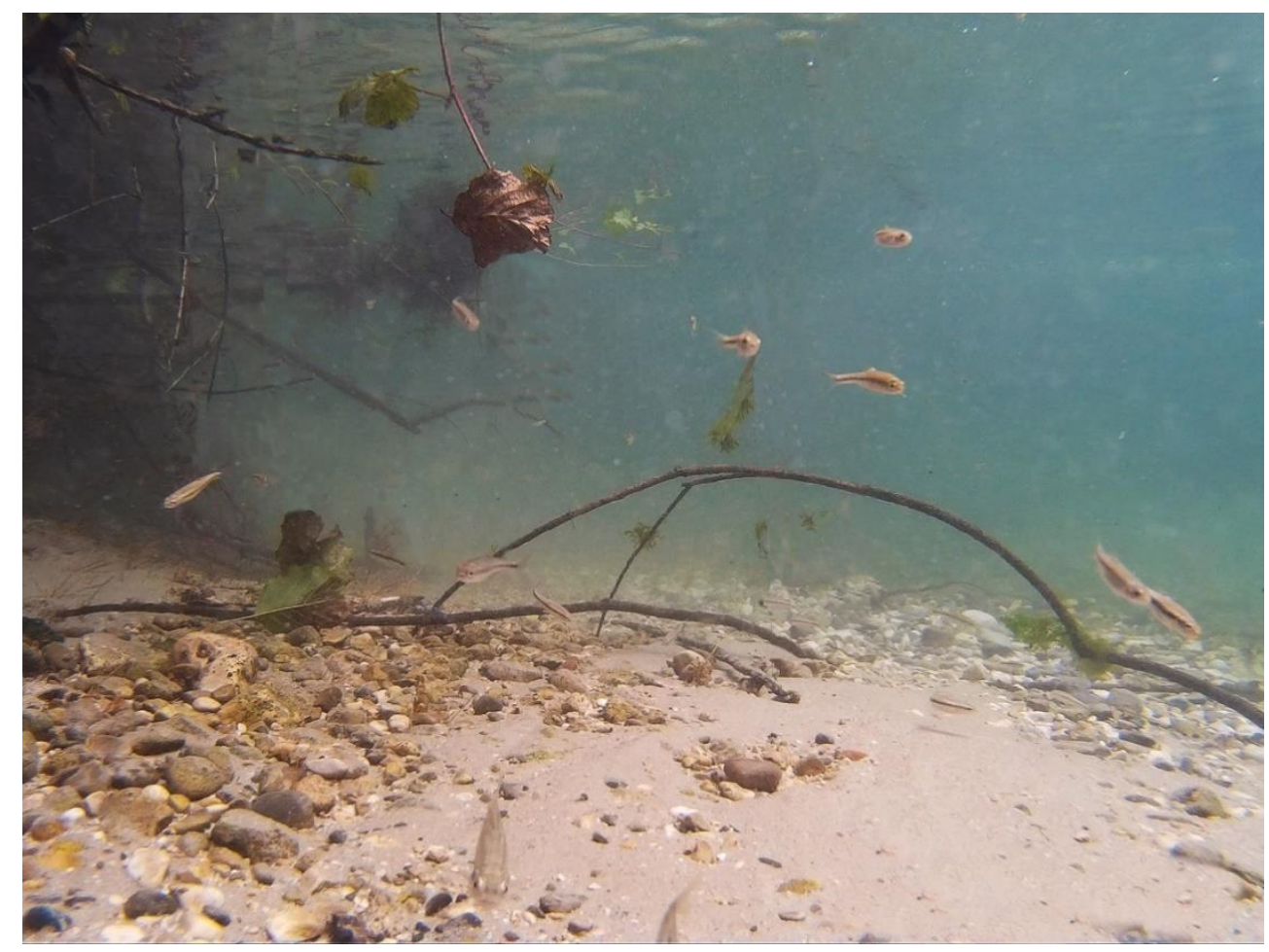

Graphical abstract caption: The two-way interactions between aquatic organisms and turbulence in rivers are complex and important, and should be considered more explicitly in the science and practice of river assessment and restoration.

\section{Introduction}

The mechanics of fluid flow exert a fundamental influence on river plants and animals, and aquatic organisms themselves modify hydrodynamic properties of flow ${ }^{1}$. In fluid dynamics, a fundamental distinction can be drawn between laminar flow regimes comprising parallel layers of fluid that 'slide' over one another with no significant mixing between layers, and turbulent flow regimes which involve significant mixing and the transfer of momentum by swirling flow structures known as eddies or vortices. Turbulent flow regimes are more mathematically complex, and are ubiquitous within rivers. The dimensionless Reynolds number (the ratio between inertial forces (mass) and viscous forces) is used to identify whether flow is laminar or turbulent, and can also be used to describe the interaction between aquatic organisms and the viscous forces of the fluid, with larger and more hydrodynamically rough body morphologies associated with higher Reynolds numbers (Figure 1). Turbulent flows, however, encompass a wide range of environmental conditions and a universally accepted definition of turbulence remains elusive. Despite this, a suite of common attributes can be identified including: enhanced mixing, sensitivity to initial conditions and small perturbations (deterministic chaos), a large range of interacting spatial and temporal structures, motions in directions other than the applied shear, rotationality, intermittency and irregularity ${ }^{2-5}$.

There has been a proliferation of turbulence studies in laboratory and field settings following the publication of accessible key texts on turbulence and boundary layer theory during the $1990 \mathrm{~s}^{1,2}$, advances in instrumentation such as Acoustic Doppler Velocimetry ${ }^{6-10}$; and development of analytical approaches to characterising turbulent properties ${ }^{11-14}$. Methodological advancements in quantifying 
turbulence have developed largely through a combination of laboratory experimentation ${ }^{15-18}$ and high-resolution field measurements over relatively small reaches $(<5 \mathrm{~m})$ of natural channels ${ }^{19}$.

$$
\operatorname{Re}=\frac{\text { Inertial forces }}{\text { Viscous forces }}=\frac{\text { fluid density } x \text { velocity } x \text { length }}{\text { dynamic viscocity }}=\frac{\rho U L}{\mu}
$$

Laminar flow Turbulent flow

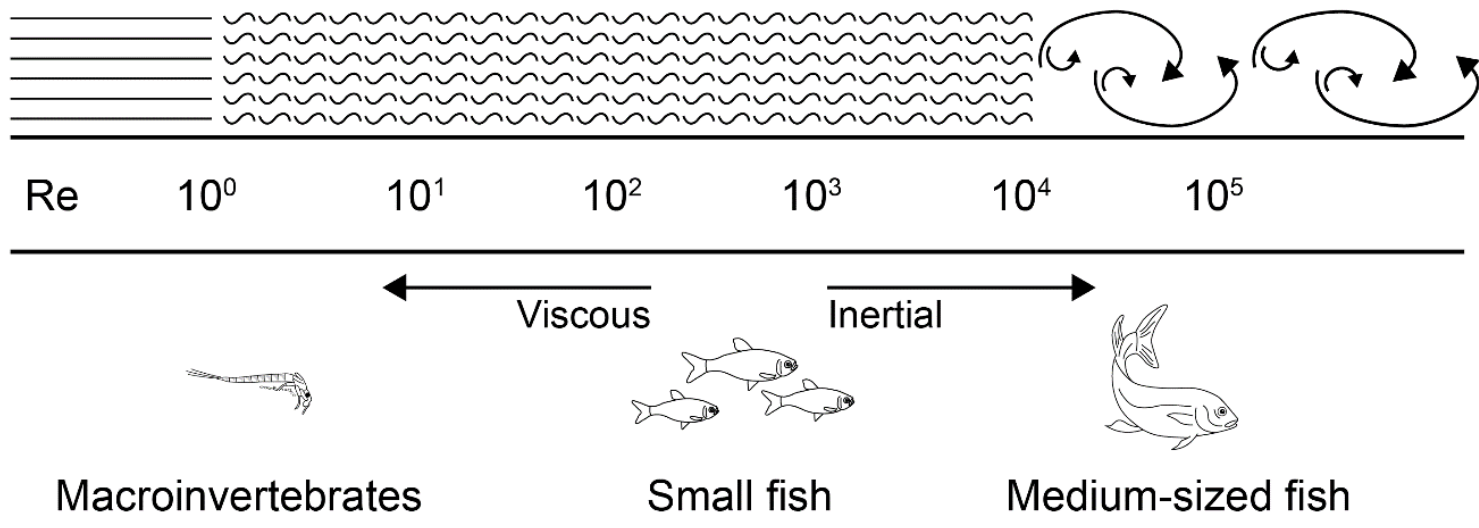

Figure 1 Definition of Reynolds number, laminar and turbulent flow, with example Reynolds numbers for different types of organisms interacting with the flow.

Turbulence is known to exert a significant influence on river flora and fauna. For example, the presence of vegetation profoundly modifies the mean and turbulent properties of flow ${ }^{20}$, while the direct consideration of turbulence has been shown to add explanatory power when assessing habitat preferences of aquatic fish ${ }^{21}$ and invertebrates ${ }^{22}$. In spite of this, there remains a disconnect between standard approaches to habitat assessment (which often rely on visual observation and/or averaged flow properties e.g. River Habitat Survey, Index for the assessment of fluvial habitat in Mediterranean rivers $^{23-25}$ ) and detailed investigation of hydrodynamics. This results in a lack of understanding of the links between turbulence and aquatic organisms at the 'mesoscale' of rivers ${ }^{26}$ where habitat assessment and restoration tends to be focused ${ }^{27}$.

This paper aims to provide a review of the current state of knowledge of interactions between biota and hydrodynamics in rivers in order to encourage more explicit consideration of hydrodynamics in river assessment and restoration design. To achieve this, we provide an overview of the approaches to research design used in this field in order to provide context for the scientific knowledge base. Turbulent boundary layer theory and parameters are briefly introduced, and the main ways in which key groups of river organisms (aquatic vegetation, macroinvertebrates and fish) interact with the turbulent properties of river flow are then explored. This includes the ways in which animals and plants modify hydrodynamics in rivers, the benefits they derive from turbulent flows and the threats that turbulence can pose to growth, survival and fitness. 


\section{Approaches to research design}

There is considerable diversity in the research approaches applied to the study of interactions between turbulence and aquatic organisms. This arises from several sources: (i) studies may involve field measurement, laboratory experimentation or hydraulic modelling; (ii) turbulence may be simulated in laboratory studies using a number of different mechanisms; (iii) laboratory experimentation may employ living or artificial organisms; and (iv) eco-physiological impacts and energetic costs for swimming and turbulence-mediated behaviour may be quantified in a range of ways. Laboratory studies are by far the most common approach, reflecting opportunities for detailed observations of organism behaviour and responses to perturbations and perhaps more importantly the advantages of tight experimental control. The latter is particularly attractive since a multitude of factors other than turbulence will influence habitat selection and bioenergetics in aquatic organisms in 'real' rivers, including endogenous factors (e.g. life cycle stage/ size, physiological state, parasite load and disease) and environmental context (e.g. light levels, temperature, availability of oxygen and nutrients, presence of toxicants, competition) ${ }^{28-31}$. Accounting for these influences under field conditions is inherently challenging.

Even within laboratory flume settings, numerous options are available for simulating and quantifying turbulence, and drawing comparisons between results arising from different experimental designs can be problematic. Mechanisms for turbulence generation within laboratory settings include varying the degree of flume boundary roughness ${ }^{32}$, modulation of flow pumps ${ }^{33}$ and the positioning of cylindrical or spherical flow obstructions ('bluff bodies') within the flow field ${ }^{34,35}$. Turbulent properties may be then quantified through point measurements of velocity sampled at high frequencies (e.g. $20 \mathrm{~Hz}$ ) using a range of sensor types ${ }^{36,26,37-40}$ or visualised and estimated using Particle Image Velocimetry (PIV) which is more straightforward to implement in the laboratory ${ }^{41,42}$ than in the field ${ }^{43,44}$. Recent advances in acoustic Doppler current profiling can provide detailed 3-dimensional hydraulics by capturing high resolution vertical profiles of semi-continuous velocity points $9,10,45,46$. A range of hydrodynamic characteristics may then be derived (see section below). The same technologies can be deployed in the field, and both field and laboratory studies must consider a number of potential sources of error when devising the sampling design: the degree of disturbance introduced into the flow by the sampling equipment, probe orientation, the sampling volume the measurement frequency and record length and post-processing accuracy ${ }^{38,26}$.

Numerical modelling approaches can also be applied and recent reviews have examined the role of numerical modelling in ecohydraulics ${ }^{47}$ and the simulation of turbulent flow ${ }^{48}$. Numerical modelling of turbulence involves solving the system of partial differential equations that represent momentum and the conservation of mass (the Navier-Stokes equations). Direct Numerical Simulation (DNS) solves the equations at the smallest scales of turbulence but the approach is computationally expensive and ecohydraulics applications have been relatively limited as a result of the lack of ecological and geomorphological understanding at this $\mathrm{scale}^{47}$. Many applications have instead used the less computationally intensive Reynold's averaged Navier-Stokes (RANS) equations to represent temporally averaged turbulence properties. Alternative approaches such as Large Eddy Simulation (LES) show promise for achieving a balance between accuracy and applicability, and computational demand $^{48}$.LES can be used to resolve the Navier-Stokes equations for most scales of interest ${ }^{49}$ and has been used to provide useful information on, for example, the turbulence structure of river 
confluences ${ }^{49-52}$, secondary flow circulation due to the presence of obstacles ${ }^{53-55}$ and sediment dynamics ${ }^{56,57}$.

Laboratory studies have used living organisms or physical models (inanimate surrogates) to explore interactions between hydrodynamics and aquatic life, while field studies naturally focus on the former. Physical models of submerged and emergent vegetation include rigid or flexible plastic rods or blades that achieve a similar geometry and rigidity to species of interest, with or without foliage, and are usually fixed to a board or the flume bed ${ }^{58-61}$. Physical models of animals have also been used in laboratory experimentation, with examples including artificial trout used to assess the hydrodynamics of entraining behaviour ${ }^{62}$ and late instar Blackfly larva (Simulium vittatum) constructed from capillary tubing ${ }^{63}$. Physical surrogates have the advantages of alleviating practical issues around husbandry and acclimatisation, cost, replication, abundance/density and positioning within the flow field as well as allowing very detailed measurements in close proximity to the 'organism' ${ }^{64}$. They are, however, a simplification of the physical structure of live organisms, capable of mimicking morphological characteristics but necessarily overlooking important biomechanical, physiological, and behavioural interactions with the flow field and with other organisms (see Johnson et al. ${ }^{64}$ for a full discussion of the use of surrogates and live animals in laboratory experimentation). For example, live animals enable detailed bioenergetics studies, with a number of options available for estimating turbulence-related energy costs. Visual observation can be used to record the critical flow rate (velocity at which the fish fatigues) ${ }^{65}$, while underwater videography captures behaviour and responses to perturbations continuously ${ }^{66,67}$, and respiratory experiments can directly quantify oxygen consumption and thus energetic losses ${ }^{33}$. Limitations of experimental approaches, however, include set-up costs, fitness-for-purpose of different equipment specifications, differences in the biogeochemical constituents of water, and difficulties in extrapolating results from short-duration, small-scale studies to greater temporal and spatial scales ${ }^{68}$.

\section{Turbulence theory and parameters}

The diversity in definitions of turbulent flows is mirrored in the variety of studies of impacts of such flows on aquatic organisms. However, quantitative descriptions of turbulence can be usefully separated into two main approaches ${ }^{26,69}$ : (i) statistical description ${ }^{2}$; and (ii) the use of spatially and temporally correlated turbulence properties to describe three dimensional coherent flow structures (CFS) or 'eddies ${ }^{70-71}$. The first approach considers turbulence as a stochastic (random) phenomenon and identifies aggregated or bulk properties of the flow. When fluid motion is viewed in a Eulerian frame (i.e. observing a specific location in space through which the fluid passes), the turbulent flow field may be represented by a velocity vector with three orthogonal components (streamwise, $u$; cross stream, v; and vertical, w), each of which can be decomposed into mean $(U, V, W)$ and fluctuating ( $u^{\prime}$, $\left.v^{\prime}, w^{\prime}\right)$ parts. Coherent flow structures can be identified through time series analysis, flow visualisation or numerical modelling ${ }^{72-75}$ and encompass small scale structures shed from individual roughness elements such as bed material grains ${ }^{74,76,77}$, to large-scale ejections of fluid away from the river bed and inrushes of fluid towards the bed ${ }^{17}$. Such turbulent macrostructures may be important in initiating and modifying river bedforms ${ }^{78,79}$. Mathematical definition of vortices is challenging, leading to the development of a range of different algorithms for investigating the presence and nature of vortices 
in the flow. Applications within ecohydraulics have included a combination of Eulerian vortex detection methods such as the $Q$ criterion (based on the magnitude of vorticity) and Langragian methods such as the Finite-time Lyapunov exponent (FTLE) method which tracks individual fluid trajectories through time ${ }^{80}$.

A recent paper by Lacey et $a l .{ }^{81}$ proposed a framework for exploring ecologically-relevant turbulent properties in river channels, focusing specifically on fishes. The "IPOS" framework ${ }^{81}$ presents four categories of turbulent characteristics: Intensity, Periodicity, Orientation and Scale which can be computed from high frequency velocity time series (Table 1). The intensity of velocity fluctuations along the three components $(u, v, w)$ can be explored by computing the root mean square of the fluctuations $\left(R M S_{u}, R M S_{v}, R M S_{w}\right)$, which may be normalised by the shear of mean velocity to provide a relative measure of the intensity of turbulent fluctuations. Turbulent Kinetic Energy combines all three components to provide an overall measure of the kinetic (movement) energy of eddies in the flow, while the Reynolds shear stresses describe the frictional forces of flow that characterize sediment mobilization and transport ${ }^{4,26,82}$.

Periodicity refers to the predictability of the flow, and the occurrence of dominant frequencies in the velocity record. A simple indicator of predictability can be gained through inspection of the kurtosis of the turbulent residuals $u^{\prime}, v^{\prime}, w^{\prime} 83$. Second order autoregressive modelling can also be applied to high frequency velocity time series with the aim of deriving a length scale for the dominant eddy (see below). This approach requires series to satisfy a condition for pseudo-periodicity ${ }^{70}$ which may be used to provide an initial indication of time series predictability. Two further approaches can be used to identify the dominant periodic structure (eddy size) or range of structures present. Spectral density analysis decomposes the velocity signal into frequencies using the Fourier Transform and can be used to provide global information on the dominant period (converted to an eddy size or 'length scale' by multiplying by the mean velocity; see below). In contrast, wavelet analysis uses the Continuous Wavelet Transform (CWT) to decompose the time series into time and frequency domains simultaneously, detecting and extracting the periodic signals in the record and how they vary through time $^{12}$. It has been suggested that the latter approach is more appropriate for coherent flow structures which may be intermittent and evolve through time and space ${ }^{81}$.

An initial indicator of flow 'orientation' can be derived from the skewness of the $u^{\prime}, v^{\prime}$ and $w^{\prime}$ components which indicates the shape of the frequency distribution of the magnitude of turbulent fluctuations. Positively skewed turbulence residuals indicate the presence of a small number of high magnitude fluctuations, which may generate favourable conditions for sediment transport ${ }^{84,85}$. The Reynolds shear stresses $\rho \overline{u^{\prime} v^{\prime}}, \rho \overline{u^{\prime} w^{\prime}}$ and $\rho \overline{v^{\prime} w^{\prime}}$ represent the turbulent flux of momentum and therefore should affect fish swimming performance and ability to hold station in the flow, but are rarely reported in ecohydraulics experiments ${ }^{81}$. More complex analysis can assign instantaneous 2D velocity ( $u$ ' and $w$ ') measurements to one of four turbulent 'events' based on Quadrant Analysis based on the relative sign of paired values of $u^{\prime}$ and $w^{\prime 86}$. In order to isolate the strongest events from those with negligible contribution to the Reynolds stress, a threshold or 'hole' may be applied, commonly twice the standard deviation of $u^{\prime} w^{\prime 2,87,26}$. The cumulative duration and stress contribution from each type of turbulent event can then be explored. 
Table 1 IPOS categories (intensity, periodicity, orientation, scale) identified by Lacey et al. ${ }^{81}$ with example variables and descriptions. * denotes additional variables to those directly identified in Lacey et al. ${ }^{81}$. Where $x=\mathrm{u}, \mathrm{v}, \mathrm{w}$ components, $N$ are the number of observations and $\rho$ is the water density, $u^{\prime}, v^{\prime}$ and $w^{\prime}$ are the turbulent residuals and $U, V, W$ the mean velocities along the three components.

\begin{tabular}{|c|c|c|}
\hline & Parameter & Description \\
\hline \multirow{6}{*}{ 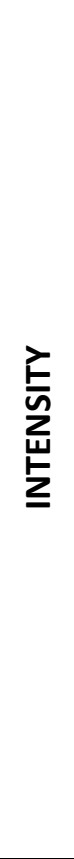 } & Turbulence intensity & $\begin{array}{l}\text { Root mean square of the turbulent fluctuations (Reynolds normal } \\
\text { stresses in the } u, v \text { and } w \text { dimension): }\end{array}$ \\
\hline & & $R M S_{x}=\sqrt{\frac{1}{N}}\left(x_{1}^{\prime 2}+x_{2}^{\prime 2}+\cdots+x_{N}^{\prime 2}\right)$ \\
\hline & $\begin{array}{l}\text { Turbulence intensity } \\
\text { (relative) }\end{array}$ & $\begin{array}{l}\text { Normalised (by shear or mean velocity) values for } \mathrm{u}, \mathrm{v}, \mathrm{w} \text { : } \\
T I_{x}=\frac{\sigma_{x}}{U}\end{array}$ \\
\hline & $\begin{array}{l}\text { Turbulent Kinetic } \\
\text { Energy }\end{array}$ & $\begin{array}{l}\text { Combines RMSu, RMSv, RMSw: } \\
T K E=\frac{1}{2} \rho\left(R M S_{x}^{2}+R M S_{x}^{2}+R M S_{x}^{2}\right)\end{array}$ \\
\hline & $\begin{array}{l}\text { Reynolds Shear } \\
\text { Stresses }\end{array}$ & $\begin{array}{l}\text { Represent the turbulent flux of momentum - may affect } \\
\text { organisms but rarely reported: } \\
\tau_{u v}=\rho \overline{u^{\prime} v^{\prime}} \tau_{u w}=\rho \overline{u^{\prime} w^{\prime}} \tau_{v w}=\rho \overline{v^{\prime} w^{\prime}}\end{array}$ \\
\hline & $\begin{array}{l}\text { Vorticity } \\
\text { (tendency to rotate) }\end{array}$ & $\begin{array}{l}\omega=2 \Omega \\
\text { Where } \Omega \text { represents the angular velocity, or rotational speed of } \\
\text { the fluid. }\end{array}$ \\
\hline \multirow{4}{*}{ 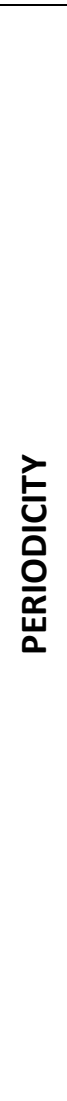 } & \multirow[b]{2}{*}{ Predictability } & $\begin{array}{l}\text { Kurtosis* of the turbulent residuals }\left(\mathrm{u}^{\prime}, \mathrm{v}^{\prime}, \mathrm{w}^{\prime}\right) \text { used as an initial } \\
\text { indicator }{ }^{77} \text { : } \\
K=\frac{\sum_{1}^{N}\left(\frac{x_{i}-\bar{x}}{\sigma}\right)^{4}}{N}\end{array}$ \\
\hline & & $\begin{array}{l}\mathrm{AR}(2) \text { models applied and the condition for pseudo-periodicity* } \\
\text { derived }{ }^{65} \text {. Average eddy frequency/ period (the integral time } \\
\text { scale) can be derived (where } \mathrm{R}(t) \text { is the normalized } \\
\text { autocorrelation function and } t \text { is the time lag): } \\
\operatorname{ITS}_{u, v, w}=\int_{0}^{\infty} R(t) d t\end{array}$ \\
\hline & \multirow[t]{2}{*}{ Energy spectra } & $\begin{array}{l}\text { Fourier transform (spectral density/ wavenumber spectra) } \\
\text { traditionally applied to qualitatively explore the shape of spectra } \\
\text { and derive the kinetic energy maximum. Involves conversion of } \\
\text { the frequency spectra into wavenumber spectra }(k) \text { using the } \\
\text { frequency domain }\left(f_{n}\right) \text { : } \\
E(k)=\frac{U}{2 \pi} S\left(f_{n}\right) \\
k=\frac{2 \pi f_{n}}{U}\end{array}$ \\
\hline & & $\begin{array}{l}\text { Wavelet analysis - a more sophisticated method, better for } \\
\text { intermittent/evolving flow structures (dominant frequency) }\end{array}$ \\
\hline
\end{tabular}




\begin{tabular}{|c|c|c|}
\hline \multirow{4}{*}{ 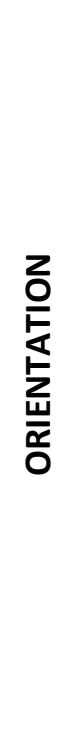 } & Skewness* & $\begin{array}{l}\text { An initial, basic indicator of flow 'orientation' can be derived } \\
\text { from the skewness of the } u^{\prime}, v^{\prime} \text { and } w^{\prime} \text { components }{ }^{82} \text {, describing } \\
\text { the asymmetry of the frequency distribution of the magnitude of } \\
\text { turbulent fluctuations on each of the three planes: } \\
K=\frac{\sum_{1}^{N}\left(\frac{x_{i}-\bar{x}}{\sigma}\right)^{3}}{N}\end{array}$ \\
\hline & Event structure* & $\begin{array}{l}\text { Duration and/or contribution to stress of each type of 'event': Q1 } \\
\text { ( } u^{\prime}>0, w^{\prime}>0 \text {; outward interactions), Q2 ( } u^{\prime}<0, w^{\prime}>0 \text {; ejections of } \\
\text { fluid away from the bed), Q3 ( } u^{\prime}<0, w^{\prime}<0 \text {; inward interactions) } \\
\text { and } Q 4 \text { ( } u^{\prime}>0, w^{\prime}<0 \text {; inrushes of fluid towards the bed). }\end{array}$ \\
\hline & $\begin{array}{l}\text { Direction of } \\
\text { dominant fluctuation }\end{array}$ & $\begin{array}{l}\text { Axis of eddy rotation - angle between the direction of dominant } \\
\text { fluctuation and the streamwise direction. }\end{array}$ \\
\hline & $\begin{array}{l}\text { Reynolds Shear } \\
\text { Stresses }\end{array}$ & $\begin{array}{l}\text { Indicating the magnitude of stress on the different planes ( } u^{\prime} v^{\prime} \text {, } \\
\left.u^{\prime} w^{\prime} \text {, and } v^{\prime} w^{\prime}\right) \text { - see above. }\end{array}$ \\
\hline \multirow{3}{*}{ 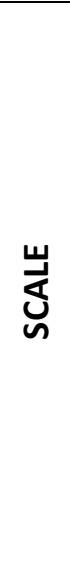 } & Eddy length scale & $\begin{array}{l}\text { Average eddy length or spatial extent of the region of correlation } \\
\text { ("wedges" of fluid). The integral time scale (see above) can be } \\
\text { converted to an average eddy length (L) using mean velocity (U) } \\
\text { and } t \text { (time): } \\
L=U t\end{array}$ \\
\hline & $\begin{array}{l}\text { Fish momentum: } \\
\text { wedge momentum } \\
\text { ratio }\end{array}$ & $\begin{array}{l}\text { Derived from the length scale }\left(\mathrm{L}_{\mathrm{u}}\right) \text { and fish length }\left(\mathrm{L}_{\mathrm{f}}\right) \text { and } \\
\text { convection velocity of the wedge }\left(\mathrm{u}_{\mathrm{e}}\right) \text { and fish velocity }\left(\mathrm{u}_{\mathrm{f}}\right) \text { : } \\
\frac{\text { Wedge momentum }}{\text { Fish momentum }}=\frac{L_{u} * u_{e}}{L_{f} * u_{f}}\end{array}$ \\
\hline & Eddy diameter & $\begin{array}{l}\text { Spatial extent of rotating fluid, often directly measured using PIV } \\
\text { techniques in the laboratory. }\end{array}$ \\
\hline
\end{tabular}

Commonly, eddy dimensions (scale) are represented by the length and the diameter that describe the extension and maximum rotation of the swirl of current movement. The integral eddy length scale is calculated as the product of mean velocity $(U)$ and the integral time scale $(t)$ : the temporal scale of turbulent eddies or period over which velocity is autocorrelated ${ }^{88}$. This assumes Taylor's 'frozen turbulence' hypothesis that a sequence of changes in velocity at a fixed location may be interpreted to represent the movement of an unchanging pattern of turbulence past that location ${ }^{89}$. The autoregressive modelling approaches described above can provide a means of computing the integral time scale (period) for the dominant eddy structure in the time series ${ }^{2}$. This can also be compared to the size of aquatic organisms (e.g. fish length) to give a momentum ratio ${ }^{81,69}$ which may be more ecologically meaningful. The eddy diameter refers to the maximum extent of the rotating flow structure, often measured directly through laboratory visualisation.

\section{Biotic feedbacks on turbulence}

Before considering the ways in which aquatic organisms (plants, invertebrates, fish) are influenced by turbulent flow, it is important to recognise that aquatic biota themselves also modify the flow field (Figure 2). Perhaps the most significant of these interactions, within the scope of this review, is the 
influence of the biomechanical properties of aquatic vegetation on turbulence (Figure 2). At the scale of stems and branches, aquatic plants convert mean kinetic energy into turbulent kinetic energy through the generation of wakes, with the nature and fractional contribution to turbulence dependent upon the morphology and flexibility of the stems ${ }^{90}$. For flexible and long-leaved plants (e.g. Sparganium emersum), the development of wakes around individual stems may be locally important in the near-bed region but the dominant mechanism of turbulence generation is related to vortex shedding in the shear zone at leaf surfaces ${ }^{5,91}$. Macrophytes can 'rescale' turbulence by breaking larger eddies into smaller ones ${ }^{92}$, as reflected in the smaller eddy sizes found within plant stands ${ }^{86}$. Turbulence intensity may increase within sparse vegetation, but tends to then decrease with increasing density as the mean flow decreases within vegetation stands ${ }^{90,93}$. This relationship is also determined by plant morphology, however, with longer and more flexible leaves capable of generating higher turbulence intensities ${ }^{94}$. Stem vibration and fluttering/ flapping can act as an additional source of turbulence at scales intermediate between the stem and canopy ${ }^{5}$.

At the canopy scale, interactions between the plant stand and the flow generates a shear layer and different regions of turbulence can be identified. Nepf and Vivoni ${ }^{58}$ distinguished between submerged and emergent regimes. Submerged regimes comprised a zone of vertical exchange with the overlying water generated by shear, and a zone of longitudinal exchange dominated by advection, while emergent regimes were characterised by the longitudinal exchange zone only. Siniscalchi et al. ${ }^{95}$ identified three zones associated with artificial plants in flume experiments. Shear-generated zones of increased turbulent energy may be present upstream and along the canopy surface, associated with high turbulence intensities for some species ${ }^{93,94}$, combined with longitudinally homogeneous zones of negative Reynold's stresses (on the streamwise/vertical plane), and an exit region at the transition to open channel conditions. Different plant morphologies can also result in different mechanisms of turbulence generation. Rigid, emergent vegetation has been shown to deflect flow in the horizontal plane, leading to the development of periodic patterns of twisting vortices known as a von Kármán vortex street and reduced downstream turbulence intensity, while flexible submerged vegetation generates vertical and horizontal shear layers downstream as a result of strong vertical circulation ${ }^{60}$. As a result, depending on plant morphology, density and environmental context, vegetation-induced changes to turbulence can alter sediment transport processes and either enhance or reduce fine sediment deposition ${ }^{92}$.

Animals also modify the flow field, although these impacts are generally considered less significant in relation to other roughness elements ${ }^{69}$. Flow separation around lotic invertebrates modifies velocity gradients and drag and lift forces ${ }^{97}$ and suspension feeding invertebrates may both passively and actively modify the flow field to generate supplies of particulate food resources. For example, turbulence surrounding the feeding appendages of larval blackfly alter particle interception rates and the flow paths taken by individual particles ${ }^{98}$ and can lead to considerable local modifications to the flow field ${ }^{99}$, while mayfly larvae can produce vortices to enhance feeding opportunities (Figure 2; see section below). Fish generate and use their own eddies in swimming through the interactions of different fins ${ }^{100}$ and, through schooling, can produce biotically-generated flows characterised by vortices shed from the propulsive wakes of individuals ${ }^{28}$. The main ways in which animals exploit these interactions are explored further below. 


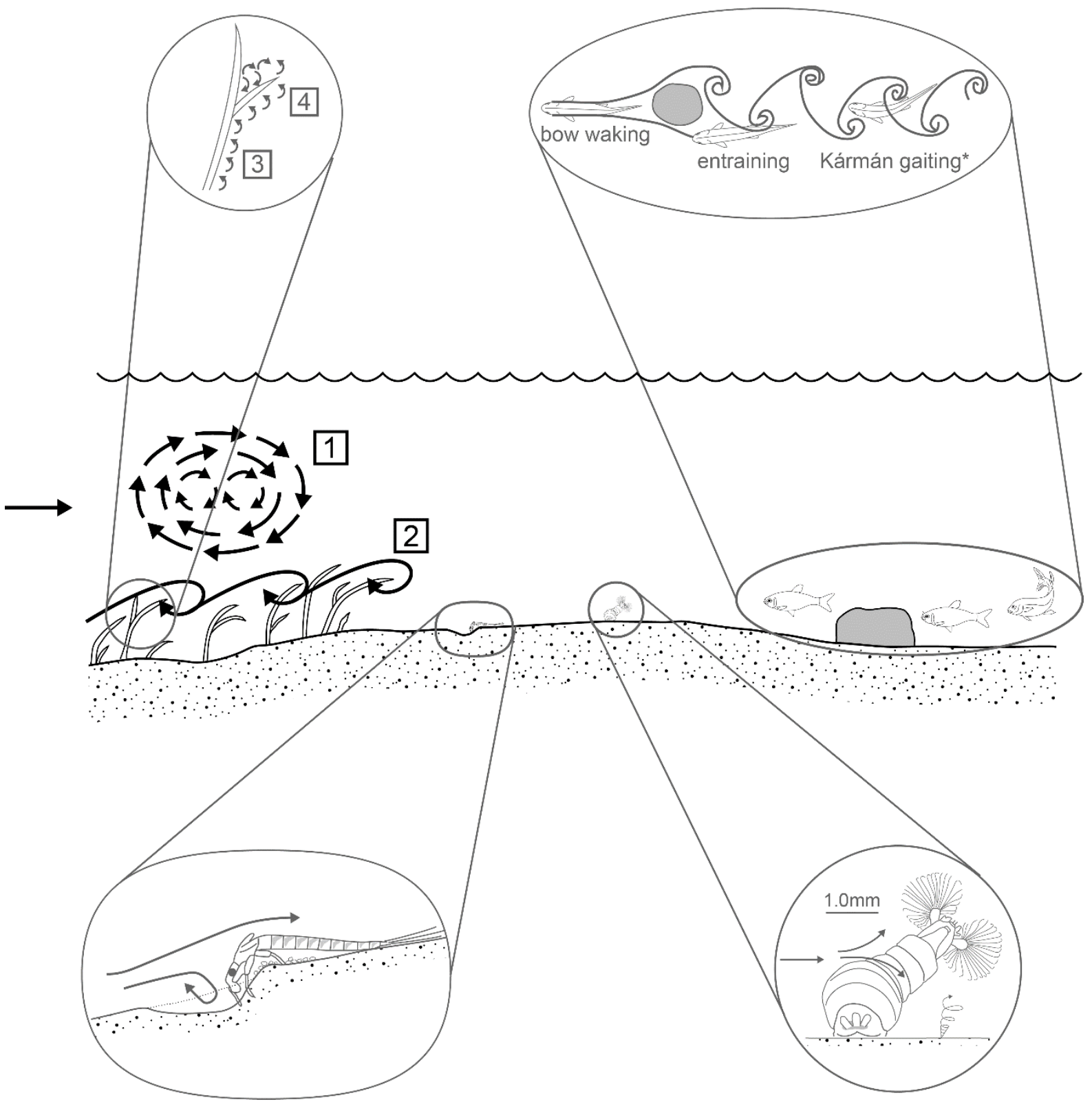

Figure $\mathbf{2}$ Interactions between flow hydrodynamics and aquatic organisms at small scales in rivers. For a aquatic plants this includes: [1] depth-scaled shear generated turbulence formed above vegetation, [2] canopy scale shear generated turbulence, [3] turbulence generated at the scale of individual stems and [4] at the scale of individual leaves, modified from Nikora ${ }^{5}$. Additional sources of turbulence associated with plant motion ${ }^{5}$ occurring at scales intermediate between the stem and canopy are not shown here. Also showing exploitation of turbulent flow structures for feeding by mayfly larvae (modified from Soluk and $\mathrm{Craig}^{101}$ ) and blackfly larvae (modified from Chance and $\mathrm{Craig}^{63}$ ) and by trout (modified from $\mathrm{LiaO}^{28}$ ) for efficient locomotion in the vicinity of bluff bodies * denotes that Kármán gaiting in trout has been observed in laboratory flumes with D-shaped cylinders rather than natural river channels. Main diagram not to scale. 


\section{Exploitation of turbulent flow properties}

Turbulent flow facilitates access to food, maintenance of adequate oxygen levels, removal of wastes, locomotion and predator evasion 1,98,100,102-108. As such, turbulence can represent a benefit rather than a constraint in many circumstance ${ }^{28}$, and can be an important consideration in aquaculture in relation to disease reduction ${ }^{109}$. Some studies indicate that even hydrodynamic conditions traditionally expected to represent a stressor or limitation can benefit some organisms. For example, in marine environments, whelks have been shown to effectively detect the odour signals of prey in flows with higher turbulence intensity that are known to confuse larger crustaceans ${ }^{108}$. In rivers, higher (average) velocities can somewhat counterintuitively reduce drift in some invertebrate species, which may reflect the gains in feeding efficiency and reductions in predation pressure that can be experienced in higher velocity areas ${ }^{110}$. With respect to aquatic plants, turbulence preferences may differ according to plant morphology ${ }^{111,112}$, but turbulent flows facilitate exchanges of solutes between plants and surrounding water to aid growth, and stimulate the epiphytic communities of bacteria, microalgae and invertebrates on plant surfaces ${ }^{94}$.

A range of animals either make vortices or use those generated by other roughness elements for movement and feeding ${ }^{1}$. Perhaps the largest body of work exploring the importance of turbulence for aquatic organisms centres on fishes, reflecting a combination of factors including the practicalities of measuring effects on larger animals as well as wider public and commercial interests. There are two main mechanisms by which rheophilic fish can exploit turbulent flows ${ }^{28}$. First, individuals can use regions of reduced velocity behind cylindrical or spherical 'bluff bodies' as flow refugia, and for station holding or 'entraining' (maintaining their position within the flow field; Figure 2). By tilting the body into the mean flow direction at a certain angle, some species may be able to maintain their position close to flow obstructions without corrective body or fin motions for short periods of time, thereby minimising energy costs ${ }^{62}$. Similarly, fin motions can generate lateral wakes helping fish to maintain balance and avoid rolling ${ }^{113,114}$. The second mechanism involves capturing the energy of discrete vortices, and is dependent upon the interaction between vortex size and fish body length ${ }^{28}$. Predictable patterns of vortex shedding (as opposed to chaotic wakes) are considered to be important here ${ }^{81}$, such as the repeating pattern of eddies known as a von Kármán vortex street that may be generated downstream of flow separation around stationary D-shaped cylinders in laboratory flumes (Figure 2). Under these conditions, eddies are shed at a certain frequency and are constrained to a relatively small range, allowing fish to recognise and anticipate flow structures ${ }^{109}$. Laboratory experiments have demonstrated that trout will adapt a novel mode of motion (the 'Kármán gait') in order to slalom in between predictable patterns of vortices shed from upstream objects ${ }^{34}$. This type of movement requires a lower tail beat frequency and allows individuals to use only the anterior axial muscles, decreasing the energetic costs of locomotion ${ }^{34}$. Turbulence generated by the propulsive movements of other fishes can also be exploited in a similar way ${ }^{28}$.

Studying the exploitation of turbulent flow structures by invertebrates is challenging as a result of the difficulties of flow measurement at the scale of individual organisms ${ }^{115}$ and within the near-bed region inhabited by benthic organisms ${ }^{98}$. Despite this, several examples of the importance of turbulent flow properties for invertebrates are available. Passive suspension feeders are an exemplar here since they 
depend upon the hydrodynamic properties of flow for the supply of food particles. Interactions between feeding appendages and other body parts, flow and transport of particulate matter are, therefore, highly important ${ }^{116}$. Blackfly larvae (Simulium vittatum), for example, can twist their bodies in order to position their specialised feeding fans at different points in the flow field (Figure 2). This allows them to exploit paired vortices generated by the flow across their bodies, with one fan capturing vortex-entrained particulate matter from the substrate, and the other filtering water from the top of the boundary layer ${ }^{63}$. Mayfly larvae can take advantage of flow perturbations generated by their bodies to excavate and utilise pits in the river bed for feeding ${ }^{101}$. For example, Pseudiron centralis can face upstream into the flow and assume an arched position, thus generating energetic horseshoe vortices which excavate a pit and expose prey such as small burrowing and interstitial invertebrates ${ }^{101}$ (Figure 2). In contrast, Ametropus neavei have been shown to orientate themselves upstream and excavate a pit which is then used in combination with their head, antennae and elevated forelegs to generate a vortex that deflects flow downward ${ }^{117}$. This enhances feeding in at least two ways: by trapping material within the swirling vortices and hence increasing the probability of capture, and by re-suspending material from within the pit. It is suggested that these mechanisms may enhance opportunities for feeding in fine-sediment dominated rivers that lack the hard substrates generally required for anchoring by filter-feeders ${ }^{117}$. Multiple organisms positioned adjacent or in the streamwise direction can exploit mutually generated hydrodynamic conditions, for example to enhance their feeding rate by concentrating flows ${ }^{63}$, or in the case of fish schooling by exploiting von Kármán trails generated by individuals upstream individuals that can reduce the energy costs of swimming ${ }^{118-121}$.

\section{Turbulence as a threat to growth and survival}

The physiological and energetic costs of turbulence to aquatic organisms are perhaps better documented than the benefits. In terms of physiological effects, intense turbulence impacting upon aquatic plants may cause tissue damage, increase respiratory costs as a result of leaf movements ${ }^{94}$, and inhibit metabolic activities and growth ${ }^{122}$. For animals, turbulence may lead to passive dislodgement from habitats. It has been shown that benthic invertebrates (e.g. Aeshna cyanea and Somatochlora flavomaculata) are sensitive to peak values of shear stress related to discrete turbulent 'events', specifically ejections of fluid away from the bed (generating upward lift forces) and inrushes of fluid towards the bed (generating lift and drag), at least where flow structures exceeded invertebrate body size ${ }^{115}$. In extreme cases, high shear stresses can cause disorientation, injury or mortality in fish ${ }^{123-125}$, but more commonly turbulence may cause linear translation of the body (i.e. displacement or drift downstream), and/ or deformation which alters the kinematics, for example via increases in tail-beat amplitude ${ }^{28}$. Turbulence can also alter predator-prey relationships in complex and contrasting ways. Intense turbulence can diminish the accuracy of strikes (and hence successful captures) as a result of reduced predictability of the location of both predator and prey, which can be costly for the predator ${ }^{126}$. Conversely, turbulence may also disrupt the lateral line system used by prey fishes to detect predators and hence potentially increase the probability of capture ${ }^{126}$, although increased turbidity as a result of turbulence can also indirectly decrease the detectability of prey. When exposed to higher turbulence intensities and shear stresses, caddisfly larvae may decrease their 
crawling speed and distance ${ }^{105}$, and other small prey also become more vulnerable to predation by fish under turbulent conditions ${ }^{127-129}$.

The influence of turbulence on fish bioenergetics (consumption, metabolism and growth) and swimming performance has received considerable attention in the literature, and has generated what appears, at first glance, to be contradictory conclusions ${ }^{69}$. For example, high turbulence intensity may increase susceptibility of perch (Perca fluviatilis) to downstream displacement ${ }^{65}$, increase swimming costs of Atlantic salmon Salmo salar ${ }^{33}$ and negatively impact upon the dynamic stability of brown trout ${ }^{67,130}$, but Nikora et al. ${ }^{32}$ found no influence of turbulence intensity on Inanga (Galaxias maculatus). Closer inspection, however, indicates that this likely reflects the variations in various aspects of the research design as outlined above: the mechanism of turbulence generation, the exact properties investigated, their relation to the physiological traits (e.g. scale) of the species and the influence of behavioural responses such as acclimatisation and learning ${ }^{20,35,69,81}$. Life cycle, sex and health may also play a role: larger and smaller guppies (Poecilia reticulata) have been shown to prefer differing levels of average velocity and turbulence, with males selected lower velocity regions possibly due to fin-induced drag, and parasite infected smaller fish selected the most stable and predictable areas of low turbulence intensity and Reynolds stresses indicating a need to offset infection-related energy $\operatorname{costs}^{30}$.

While a number of studies have focused on the influence of turbulence intensity or turbulent kinetic energy on fishes, there is increasing evidence to suggest that the size of vortices relative to fish size is one of the key factors influencing energy costs ${ }^{69,100,124}$ (Figure 3). Fish length is generally used to represent size, reflecting the importance of the 'lateral line' system of sense organs that runs lengthwise from the gills to the tail and is required for orientation, predation and coordinated swimming (schooling). Webb and Cotel $^{107}$ note the inverse relationship between eddy size and frequency and suggest that the largest and smallest eddies may be less significant for fish, since the largest flow structures may be perceived as similar to still water and the smallest are unlikely to generate stability problems. Eddies in the intermediate range may (depending on their size relative to fish body length), however, require corrections to stabilise position or may even overwhelm the ability of a fish to stabilise itself ${ }^{107}$. For example, Silva et al. ${ }^{124}$ emphasised the importance of eddies roughly equal to the body size of adult Iberian barbel (Luciobarbus bocagei), while vortices approximately $2 / 3$ fish length affect the balance of perch ( $P$. fluviatilis) leading to stabilising fin movements that increase hydraulic resistance and decrease swimming speeds ${ }^{65}$. Similarly, Tritico and Cotel ${ }^{67}$ found that stability challenges were not identifiable until the largest eddies reached $76 \%$ of the fish body length. Under such conditions fish lost postural control, spinning and translating downstream along the rotational axis of the largest eddies ('spilling'). A related quantity, the length of time a fish is exposed to the eddy, may also be important and can be considered as 'persistence' or the number of eddy rotations that occur during the time it takes a fish to move one body length through the flow ${ }^{69}$.

The orientation of flow structures can also exert important influences on fish behaviour and energetics ${ }^{81}$. Streamwise vortices (where the axis of rotation is aligns with the main flow direction) can be expected to cause rolling (perhaps the most costly), cross stream, horizontal vortices are associated with pitching and vertical vortices with yawing ${ }^{35}$. Streamwise vortices have been shown to destabilise the position of bluegill sunfish (Lepomis macrochirus), causing an increased frequency of spills and unsteady swimming manoeuvres (e.g. forward acceleration and side-to-side movements) 
and hence increased oxygen consumption, although fish could partially adapt after a period of acclimatisation ${ }^{35}$. The horizontal component of the Reynolds shear stress $\left(\rho \overline{u^{\prime} v^{\prime}}\right)$ has been identified as a key parameter in hydraulic habitat selection for smaller Iberian barbel (L. bocagei), suggesting that this could be an important consideration in artificial fishway design ${ }^{131}$.

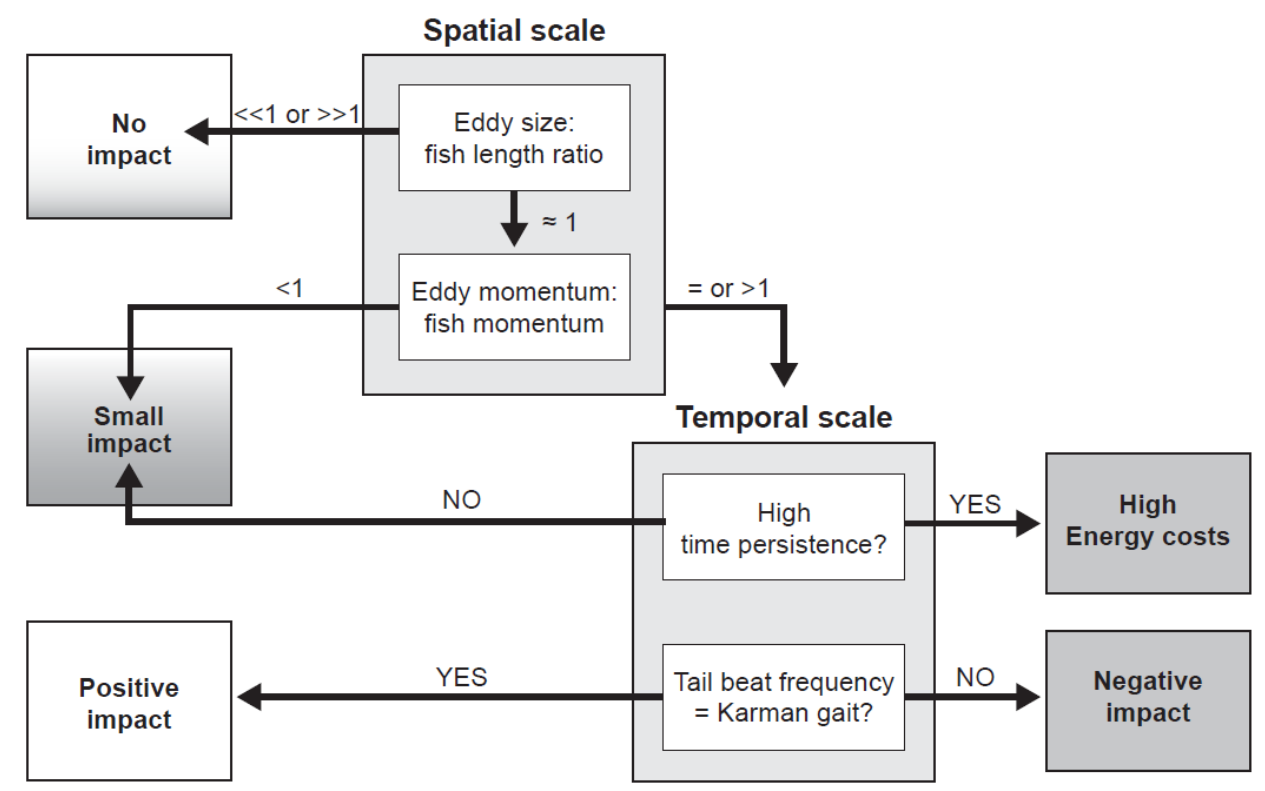

Figure 3 Decision tree illustrating how the spatial and temporal scales of eddies, combined with fish dimensions, influence the nature and magnitude of impacts on fish bioenergetics. Modified from Cotel and Webb ${ }^{69}$.

\section{Future directions}

This review has demonstrated the wide ranging and important interactions between high frequency flow properties and aquatic plants and animals in rivers, illustrating the importance of turbulence in generating suitable hydraulic habitat conditions and how organisms exploit different properties of the flow to maximise feeding and energy efficiency. The number of studies explicitly considering turbulent properties within the context of river habitat assessment and improvement, however, are relatively few $^{17,79,83,87,132-137}$. This partly reflects the practical difficulties associated with extensive field measurement of flow velocity at frequencies and record lengths sufficient to derive turbulent parameters ${ }^{38}$, as well as across different flow stages and at scales relevant to individual organisms ${ }^{98,115}$. As a result, approaches to habitat assessment tend to focus on spatially and temporally averaged conditions at a single point in time (e.g. average velocity, flow depth) instead of the 'higher order' properties of the flow ${ }^{87}$ over varying discharges.

Relationships between average flow velocity and turbulence, however, are complex and unclear, ranging from positive correlations ${ }^{83,138}$ to negative correlations ${ }^{130,134}$, and are influenced by additional factors such as bedform roughness ${ }^{133}$. This suggests that standard hydraulic variables such as velocity and depth cannot be universally applied to provide reliable estimates of more complex turbulent flow 
properties which have greater ecological relevance ${ }^{81}$. This may partly explain why aquatic communities (e.g. macroinvertebrates) appear to 'map' onto visually identifiable geomorphic units in rivers (e.g. riffles, pools, cascades), while the hydraulics of those units have been difficult to define $\mathrm{e}^{139}$. Direct consideration of turbulence has been shown to add discriminatory power when exploring habitat preferences and distributions of both fish $^{20}$ and invertebrates ${ }^{22}$, illustrating the potential benefits of achieving better integration of "hydrodynamics into ecohydraulics" 26 . The parameters discussed in this paper in relation to the IPOS framework constitute a wide-ranging portfolio of turbulence properties. These range from simpler time-averaged measures such as Turbulent Kinetic Energy and Reynolds Stresses, to analysis in the time and frequency domains, to the extraction of vortex characteristics within a Langrangian frame of reference. Increasing sophistication of turbulence descriptors is necessarily associated with increasing analytical demands, and the suite of metrics appropriate to a particular study will depend on the questions posed. It is hoped that advances in data acquisition, numerical codes and computer hardware ${ }^{47}$ will help to facilitate more widespread application within river assessment and restoration contexts, as well as river science.

High specification laboratory facilities continue to offer important opportunities for tightly controlled experimental approaches in this field. In addition to more quantitative studies, there is a place for more qualitative observational work which can yield important insights into organism behaviour and responses. It is also crucial that field research is developed further, despite the inherent practical challenges. The availability of robust sensors that have minimal interference with the flow field can assist in this regard, and ongoing developments for adaptation of PIV methods for widespread field use represent a potential step-change. Such methods enable direct capture of the spatiotemporally evolving characteristics of coherent flow structures as opposed to their computation from time series data at a single location. Underwater videography offers a low-cost option for observational work under field conditions, which can be enhanced through links with smartphone technology ${ }^{140}$ but extraction of organism movements and behaviour remains problematic due to the inability of many automated motion tracking software packages to filter out interference from ambient sources. Numerical modelling can simulate the detail of turbulent motion or its overall effect on the mean flow. While DNS provides the most detailed description of turbulence, wider application requires major developments in computing. In many applications, however, LES or hybrid LES-RANS approaches can offer a good alternative by achieving the accuracy of LES and the processing speed of RANS ${ }^{48}$. Widespread application of more detailed 3D modelling approaches within ecohydraulics also relies on developing a deep understanding of the links between turbulence and aquatic habitat at small scales to take advantage of the full dimensionality provided by the data sets ${ }^{47}$. We hope this paper can contribute to these and other developments by providing an overview of the current state of knowledge on the interactions between hydrodynamics and aquatic biota in rivers.

\section{Acknowledgements}

We thank Ed Oliver, School of Geography at Queen Mary University of London for producing the figures for this paper. This research was carried out within the Erasmus Mundus Doctorate Program SMART (http://www.riverscience.it) funded by the Education, Audiovisual and Culture Executive Agency (EACEA) of the European commission. 


\section{Figures and Captions}

Figure 1 Definition of Reynolds number and laminar and turbulent flow, with example Reynolds numbers for different types of organisms interacting with the flow.

Figure 2 Interactions between flow hydrodynamics and aquatic organisms at small scales in rivers. For aquatic plants this includes: [1] depth-scaled shear generated turbulence formed above vegetation, [2] canopy scale shear generated turbulence, [3] turbulence generated at the scale of individual stems and [4] at the scale of individual leaves, modified from Nikora ${ }^{5}$. Additional sources of turbulence associated with plant motion ${ }^{5}$ occurring at scales intermediate between the stem and canopy are not shown here. Also showing exploitation of turbulent flow structures for feeding by mayfly larvae (modified from Soluk and Craig ${ }^{96}$ ) and blackfly larvae (modified from Chance and Craig ${ }^{60}$ ) and by trout (modified from Liao $^{28}$ ) for efficient locomotion in the vicinity of bluff bodies *denotes that Kármán gaitin in trout has been observed in laboratory flumes with D-shaped cylinders rather than natural river channels. Main diagram not to scale.

Figure 3 Decision tree illustrating how the spatial and temporal scales of eddies, combined with fish dimensions, influence the nature and magnitude of impacts on fish bioenergetics. Modified from Cotel and Webb ${ }^{65}$.

\section{Tables}

Table 1 IPOS categories (intensity, periodicity, orientation, scale) identified by Lacey et al. ${ }^{75}$ with example variables and descriptions. * denotes additional variables to those identified in Lacey et $a l .{ }^{76}$. Where $\mathrm{x}=\mathrm{u}, \mathrm{v}, \mathrm{w}$ components, $\mathrm{N}$ are the number of observations and $\rho$ is the water density, $\mathrm{u}^{\prime}$, $\mathrm{V}^{\prime}$ and $\mathrm{w}^{\prime}$ are the turbulent residuals and $\mathrm{U}, \mathrm{V}, \mathrm{W}$ the mean velocities along the three components.

\section{References}

${ }^{1}$ Vogel, S. 1994. Life in moving fluids: the physical biology of flow, Princeton University Press.

${ }^{2}$ Clifford, N. J., French, J. R. and Hardisty, J. 1993. (eds.) Turbulence: Perspectives on Flow and Sediment Transport. John Wiley \& Sons.

34. ${ }^{3}$ Warhaft, Z. 2002. Turbulence in nature and in the laboratory. Proceedings of the National Academy of Sciences, 99, 2481-2486.

${ }^{4}$ Davidson, P. 2004. Turbulence: an introduction for scientists and engineers, Oxford University Press, USA.

${ }^{5}$ Nikora, V. 2010. Hydrodynamics of aquatic ecosystems: an interface between ecology, biomechanics and environmental fluid mechanics. River Research and Applications, 26, 367-384.

${ }^{6}$ Nortek, A. 1998. ADV operation manual. Vollen, Norway. 
${ }^{7}$ Lane, S., Biron, P., Bradbrook, K., Butler, J., Chandler, J., Crowell, M., McLelland, S., Richards, K. \& Roy, A. 1998. Three-dimensional measurement of river channel flow processes using acoustic Doppler velocimetry. Earth Surface Processes and Landforms, 23, 1247-1267.

${ }^{8}$ Voulgaris, G. \& Trowbridge, J. H. 1998. Evaluation of the acoustic Doppler velocimeter (ADV) for turbulence measurements. Journal of Atmospheric and Oceanic Technology, 15, 272-289.

${ }^{9}$ Garcia, C. M., Cantero, M. I., Nino, Y. \& Garcia, M. H. 2005. Turbulence measurements with acoustic Doppler velocimeters. Journal of Hydraulic Engineering, 131, 1062-1073.

${ }^{10}$ Chanson, H. 2008. Acoustic Doppler velocimetry (ADV) in the field and in laboratory: practical experiences. International Meeting on Measurements and Hydraulics of Sewers IMMHS'08, Summer School GEMCEA/LCPC. Department of Civil Engineering, University of Queensland, 49-66.

${ }^{11}$ Farge, M. 1992. Wavelet transforms and their applications to turbulence. Annual Review of Fluid Mechanics, 24, 395-458.

${ }^{12}$ Torrence, C. \& Compo, G. P. 1998. A practical guide to wavelet analysis. Bulletin of the American Meteorological society, 79, 61-78.

${ }^{13}$ McLelland, S. J. \& Nicholas, A. P. 2000. A new method for evaluating errors in high frequency ADV measurements. Hydrological Processes, 14, 351-366.

${ }^{14}$ Goring, D. G. \& Nikora, V. I. 2002. Despiking acoustic Doppler velocimeter data. Journal of Hydraulic Engineering, 128, 117-126.

${ }^{15} \mathrm{Nezu}$, I. \& Nakagawa, H. 1995. Turbulence measurements in unsteady free-surface flows. Flow Measurement and Instrumentation, 6, 49-59.

${ }^{16}$ Adrian, R. J. 2007. Hairpin vortex organization in wall turbulencea). Physics of Fluids (1994present), 19, 041301.

${ }^{17}$ Hardy, R. J., Best, J. L., Lane, S. N. \& Carbonneau, P. E. 2009. Coherent flow structures in a depthlimited flow over a gravel surface: The role of near-bed turbulence and influence of Reynolds number. Journal of Geophysical Research: Earth Surface, 114, F01003.

${ }^{18}$ Jimenez, J. 2011. Cascades in wall-bounded turbulence. Annual Review of Fluid Mechanics, 44, 2745.

${ }^{19}$ Buffin-Belanger, T. \& Roy, A. G. 1998. Effects of a pebble cluster on the turbulent structure of a depth-limited flow in a gravel-bed river. Geomorphology, 25, 249-267.

${ }^{20} \mathrm{Nepf}, \mathrm{H}$. M. 2012 Flow and transport in regions with aquatic vegetation. Annual Review of Fluid Mechanics 44: 123-142.

${ }^{21}$ Smith, D. L., Goodwin, R. A. \& Nestler, J. M. 2014. Relating turbulence and fish habitat: a new approach for management and research. Reviews in Fisheries Science \& Aquaculture, 22, 123-130. 
${ }^{22}$ Morris, M., Mohammadi, M. H., Day, S., Hondzo, M. \& Sotiropulus, F. 2015. Prediction of Glossosoma biomass spatial distribution in Valley Creek by field measurements and a threedimensional turbulent open-channel flow model. Water Resources Research, 51, 1457-1471.

${ }^{23}$ Raven, P., Holmes, N., Dawson, F. \& Everard, M. 1998. Quality assessment using River Habitat Survey data. Aquatic Conservation: Marine and Freshwater Ecosystems, 8, 477-499.

${ }^{24}$ Pardo, I., Alvarez, M., Casas, J., Moreno, J., Vivas, S., Bonada, N., Alba-Tercedor, J., Jaimez-Cuellar, P., Moya, G. \& Prat, N. 2002. The habitat of the Mediterranean rivers. Design of the habitat diversity index. Limnetica, 21, 115-133.

${ }^{25}$ Rinaldi, M., Belletti, B., Van De Bund, W., Bertoldi, W., Gurnell, A., Bujse, T. \& Mosselman, E. 2013. Review on eco-hydromorphological methods. Deliverable, D1.1, 2007-2013. Available at: http://www.reformrivers.eu/deliverables/d1-1.

${ }^{26}$ Wilkes, M. A., Maddock, I., Visser, F. \& Acreman, M. C. 2013. Incorporating hydrodynamics into ecohydraulics: the role of turbulence in the swimming performance and habitat selection of streamdwelling fish. In: Maddock, I., Harbym A., Kemp, P. and Wood, P. (eds). Ecohydraulics: An Integrated Approach. John Wiley \& Sons, Ltd, 9-30.

${ }^{27}$ Newson, M. \& Newson, C. 2000. Geomorphology, ecology and river channel habitat: mesoscale approaches to basin-scale challenges. Progress in Physical Geography, 24, 195-217.

${ }^{28}$ Liao, J. C. 2007. A review of fish swimming mechanics and behaviour in altered flows. Philosophical Transactions of the Royal Society B: Biological Sciences, 362, 1973-1993.

${ }^{29}$ MCKenzie, D. \& Claireaux, G. 2010. The effects of environmental factors on the physiology of aerobic exercise. In: Domenici, P. and Kapoor, B. (eds). Fish locomotion: an eco-ethological perspective. CRC Press, Enfield, 296-332.

${ }^{30}$ Hockley, F. A., Wilson, C., Brew, A. \& Cable, J. 2014. Fish responses to flow velocity and turbulence in relation to size, sex and parasite load. Journal of the Royal Society Interface, 11, 20130814.

${ }^{31}$ Shuter, B. J., Finstad, A. G., Helland, I. P., Zweimüller, I., \& Hölker, F. 2012. The role of winter phenology in shaping the ecology of freshwater fish and their sensitivities to climate change. Aquatic Sciences, 74(4), 637-657.

${ }^{32}$ Nikora, V., Aberle, J., Biggs, B., Jowett, I. \& Sykes, J. 2003. Effects of fish size, time-to-fatigue and turbulence on swimming performance: a case study of Galaxias maculatus. Journal of Fish Biology, $63,1365-1382$.

${ }^{33}$ Enders, E. C., Boisclair, D. \& Roy, A. G. 2003. The effect of turbulence on the cost of swimming for juvenile Atlantic salmon (Salmo salar). Canadian Journal of Fisheries and Aquatic Sciences, 60, 11491160.

${ }^{34}$ Liao, J. C., Beal, D. N., Lauder, G. V. \& Triantafyllou, M. S. 2003. Fish exploiting vortices decrease muscle activity. Science, 302, 1566-1569. 
${ }^{35}$ Maia, A., Sheltzer, A. P. \& Tytell, E. D. 2015. Streamwise vortices destabilize swimming bluegill sunfish (Lepomis macrochirus). Journal of Experimental Biology, 218, 786-792.

${ }^{36}$ Clifford, N. \& French, J. 1993. Monitoring and modelling turbulent flows: historical and contemporary perspectives. In: Clifford, N. J., French, J. R. and Hardisty, J. (eds.) Turbulence: Perspectives on Flow and Sediment Transport. John Wiley \& Sons: 1-34.

${ }^{37}$ Lane, S., Bradbrook, K., Richards, K., Biron, P. \& Roy, A. 1999. The application of computational fluid dynamics to natural river channels: three-dimensional versus two-dimensional approaches. Geomorphology, 29, 1-20.

${ }^{38}$ Buffin- Belanger, T. \& Roy, A. G. 2005. 1 min in the life of a river: selecting the optimal record length for the measurement of turbulence in fluvial boundary layers. Geomorphology, 68, 77-94.

${ }^{39}$ Sulaiman, M., Sinnakaudan, S. \& Shukor, M. 2013. Near bed turbulence measurement with acoustic doppler velocimeter (ADV). KSCE Journal of Civil Engineering, 17, 1515-1528.

${ }^{40}$ Stewart, R. L. \& Fox, J. F. 2015. Role of macroturbulence to sustain turbulent energy in decelerating flows over a gravel bed. Geomorphology, 248, 147-160.

${ }^{41}$ Creutin, J., Muste, M., Bradley, A., Kim, S. \& Kruger, A. 2003. River gauging using PIV techniques: a proof of concept experiment on the lowa River. Journal of Hydrology, 277, 182-194.

${ }^{42}$ Adrian, R. J. 2005. Twenty years of particle image velocimetry. Experiments in Fluids, 39, 159-169.

${ }^{43}$ Tritico, H., Cotel, A. \& Clarke, J. 2007. Development, testing and demonstration of a portable submersible miniature particle imaging velocimetry device. Measurement Science and Technology, 18, 2555.

${ }^{44}$ Fox, J. \& Patrick, A. 2008. Large-scale eddies measured with large scale particle image velocimetry. Flow measurement and Instrumentation, 19, 283-291.

${ }^{45}$ Nystrom, E. A., Oberg, K. A. \& Rehmann, C. R. Measurement of turbulence with acoustic Doppler current profilers-Sources of error and laboratory results. Proc., Hydraulic Measurements \& Experimental Methods 2002, 2002. ASCE Reston, Va.

${ }^{46}$ Rusello, P. J., Lohrmann, A., Siegel, E. \& Maddux, T. 2006. Improvements in acoustic Doppler velocimetery. 7th International Conferrence on Hydroscience and Engineering (ICHE-2006), Sep $10-$ Sep 13, Philadelphia, USA.

${ }^{47}$ Tonina, D. \& Jorde, K. (2013) Hydraulic modelling approaches for ecohydraulic studies: 3D, 2D, 1D and non-numerical models. In: Maddock, I., Harby, A., Kemp, P. and Wood, P. (eds) Ecohydraulics: An Integrated Approach. John Wiley \& Sons Ltd.

${ }^{48}$ Argyropoulos, C. D. \& Markatos, N. C. (2015) Recent advances on the numerical modelling of turbulent flows. Applied Mathematical Modelling 39: 693-732.

${ }^{49}$ Rodi, W., Constantinescu, G. \& Stoesser, T. 2013. Large-eddy simulation in hydraulics, CRC Press. 
${ }^{50}$ Bradbrook, K., Biron, P., Lane, S., Richards, K. \& Roy, A. 1998. Investigation of controls on secondary circulation in a simple confluence geometry using a three-dimensional numerical model. Hydrological Processes, 12, 1371-1396.

${ }^{51}$ Rhoads, B. L. \& Sukhodolov, A. N. 2004. Spatial and temporal structure of shear layer turbulence at a stream confluence. Water Resources Research, 40, W06304.

${ }^{52}$ Constantinescu, G., Miyawaki, S., Rhoads, B., Sukhodolov, A. \& Kirkil, G. 2011. Structure of turbulent flow at a river confluence with momentum and velocity ratios close to 1: Insight provided by an eddy-resolving numerical simulation. Water Resources Research, 47, W05507.

${ }^{53}$ Papanicolaou, A. N., Elhakeem, M. \& Hilldale, R. 2007. Secondary current effects on cohesive river bank erosion. Water Resources Research, 43, W12418.

${ }^{54}$ Brevis, W., Garcia-Villalba, M. \& Nino, Y. 2014. Experimental and large eddy simulation study of the flow developed by a sequence of lateral obstacles. Environmental Fluid Mechanics, 14, 873-893.

${ }^{55}$ Ramon, C., Prats, J. \& Rueda, F. 2015. Simulation of Turbulent Flows in River Confluences and Meandering Channels with a Cartesian 3D Free Surface Hydrodynamic Model. International Journal of Computational Methods, 12, 1550035.

${ }^{56} \mathrm{Wu}$, W., Rodi, W. \& Wenka, T. 2000. 3D numerical modeling of flow and sediment transport in open channels. Journal of Hydraulic Engineering, 126, 4-15.

${ }^{57}$ Duc, B. M., Wenka, T. \& Rodi, W. 2004. Numerical modeling of bed deformation in laboratory channels. Journal of Hydraulic Engineering, 130, 894-904.

${ }^{58} \mathrm{Nepf}, \mathrm{H}$. \& Vivoni, E. 2000. Flow structure in depth-limited, vegetated flow. Journal of Geophysical Research: Oceans, 105, 28547-28557.

${ }^{59}$ Wilson, C., Stoesser, T., Bates, P. \& Pinzen, A. B. 2003. Open channel flow through different forms of submerged flexible vegetation. Journal of Hydraulic Engineering, 129, 847-853.

${ }^{60}$ Ortiz, A. C., Ashton, A. \& Nepf, H. 2013. Mean and turbulent velocity fields near rigid and flexible plants and the implications for deposition. Journal of Geophysical Research: Earth Surface, 118, 2585-2599.

${ }^{61}$ Li, Y., Wang, Y., Anim, D. O., Tang, C., Du, W., Ni, L., Yu, Z. \& Acharya, K. 2014. Flow characteristics in different densities of submerged flexible vegetation from an open-channel flume study of artificial plants. Geomorphology, 204, 314-324.

${ }^{62}$ Przybilla, A., Kunze, S., Rudert, A., Bleckmann, H. \& Brucker, C. 2010. Entraining in trout: a behavioural and hydrodynamic analysis. Journal of Experimental Biology, 213, 2976-2986.

${ }^{63}$ Chance, M. \& Craig, D. 1986. Hydrodynamics and behaviour of Simuliidae larvae (Diptera). Canadian Journal of Zoology, 64, 1295-1309.

${ }^{64}$ Johnson, M. F., Thomas R. E., Dijkstra, J. T., Paul, M., Penning, W. E. and Rice, S. P. Using surrogates, including scaling issues, in laboratory flumes and basins. In: Frostick, L.E., Thomas, R.E., 
Johnson, M.F., Rice, S.P. \& McLelland, S. (eds) Users Guide to Ecohydraulic Modelling and Experimentation: Experience of the Ecohydraulic Research Team (PISCES) of the HYDRALAB Network CRC Press, Leiden, The Netherlands.

${ }^{65}$ Lupandin, A. 2005. Effect of flow turbulence on swimming speed of fish. Biology Bulletin, 32, 461466.

${ }^{66}$ Standen, E. \& Lauder, G. 2007. Hydrodynamic function of dorsal and anal fins in brook trout (Salvelinus fontinalis). Journal of Experimental Biology, 210, 325-339.

${ }^{67}$ Tritico, H. \& Cotel, A. 2010. The effects of turbulent eddies on the stability and critical swimming speed of creek chub (Semotilus atromaculatus). The Journal of Experimental biology, 213, 22842293.

${ }^{68}$ Thomas, R. E., Johnson, M. F., Frostick, L. E., Parsons, D. R., Bouma, T. J., Dijkstra, J. T., Eiff, O., Gobert, S., Henry, P.-Y. \& Kemp, P. 2014. Physical modelling of water, fauna and flora: knowledge gaps, avenues for future research and infrastructural needs. Journal of Hydraulic Research, 52, 311325.

${ }^{69} \mathrm{Cotel}$, A. \& Webb, P. Living in a turbulent world-Impacts on fish habitat choices and swimming. Integrative and comparative biology, 2015. Oxford Univ press inc journals dept, 2001 Evans RD, Cary, NC 27513 USA, E36-E36.

${ }^{70}$ Richards, K. S. Stochastic processes in one-dimensional series: an introduction. 1979. Geo Abstracts, University of East Anglia.

${ }^{71}$ Ferguson, R., Kirkbride, A. \& Roy, A. 1996. Markov analysis of velocity fluctuations in gravel-bed rivers. In: Ashworth, P., Bennett, S. J., Best, J. L. \& McLelland, S. (eds). Coherent Flow Structures in Open Channels, John Wiley \& Sons Ltd, 165-183.

${ }^{72}$ Roy, A. G., Buffin-Belanger, T., Lamarre, H. \& Kirkbride, A. D. 2004. Size, shape and dynamics of large-scale turbulent flow structures in a gravel-bed river. Journal of Fluid Mechanics, 500, 1-27.

${ }^{73}$ Shvidchenko, A. B. \& Pender, G. 2001. Macroturbulent structure of open-channel flow over gravel beds. Water Resources Research, 37, 709-719.

${ }^{74} \mathrm{Best}, \mathrm{J} .1993$. On the interactions between turbulent flow structure, sediment transport and bedform development: some considerations from recent experimental research. In: Clifford, N. J., French, J. R. and Hardisty, J. (Eds.) Turbulence: Perspectives on Flow and Sediment Transport, John Wiley \& Sons, 61-92.

${ }^{75}$ Hardy, R. J., Lane, S. N., Ferguson, R. I. \& Parsons, D. R. 2007. Emergence of coherent flow structures over a gravel surface: A numerical experiment. Water Resources Research, 43.

${ }^{76}$ Roy, A. G., Buffin-Belanger, T. \& Deland, S. 1996. Scales of turbulent coherent flow structures in a gravel-bed river. In: Ashworth, P., Bennett, S. J., Best, J. L. \& McLelland, S. (eds). Coherent flow structures in open channels, John Wiley \& Sons Ltd, 147-164. 
${ }^{77}$ Clifford, N., Robert, A. \& Richards, K. 1992. Estimation of flow resistance in gravel bedded rivers: A physical explanation of the multiplier of roughness length. Earth Surface Processes and Landforms, $17,111-126$.

${ }^{78}$ Thompson, D. M., Nelson, J. M. \& Wohl, E. E. 1998. Interactions between pool geometry and hydraulics. Water Resources Research, 34, 3673-3681.

${ }^{79}$ MacVicar, B. \& Roy, A. 2007b. Hydrodynamics of a forced riffle pool in a gravel bed river: 2. Scale and structure of coherent turbulent events. Water resources research, 43, W12402.

${ }^{80}$ Marjoribanks, T. I., Hardy, R. J., Lane, S. N. \& Parsons, D. R. (2016) Does the canopy mixing layer model apply to highly flexible vegetation? Insights from numerical modelling. Environmental Fluid Mechanics doi:10.1007/s10652-016-9482-z.

${ }^{81}$ Lacey, R.W.J., Neary, V.S., Liao, J.C., Enders, E.C. \& Tritico, H.M.. 2012. The IPOS Framework: linking fish swimming performance in altered flows from laboratory experiments to rivers. River Research and Applications 28: 429-443.

${ }^{82}$ Pope, N., Widdows, J. \& Brinsley, M. 2006. Estimation of bed shear stress using the turbulent kinetic energy approach a comparison of annular flume and field data. Continental Shelf Research, 26, 959-970.

${ }^{83}$ Wilkes, M. 2014. The Hydrodynamics of River Ecosystems: Towards an Objective and Ecologically Relevant Classification of Mesohabitats. University of Worcester.

${ }^{84}$ Bagnold RA. 1966. An approach to the sediment transport problem from general physics. US Geological Survey Professional Paper 422-I.

${ }^{85}$ Leeder MR. 1983. On the dynamics of sediment suspension by residual Reynolds stressesconfirmation of Bagnold's theory. Sedimentology 40: 485-491.

${ }^{86} \mathrm{Lu}, \mathrm{S} . \&$ Willmarth, W. 1973. Measurements of the structure of the Reynolds stress in a turbulent boundary layer. Journal of Fluid Mechanics, 60, 481-511.

${ }^{87}$ Harvey, G. L. \& Clifford, N. J. 2009. Microscale hydrodynamics and coherent flow structures in rivers: implications for the characterization of physical habitat. River Research and Applications, 25, 160-180.

${ }^{88}$ Lacey, R. W. J. \& Roy, A. G. 2008. Fine-scale characterization of the turbulent shear layer of an instream pebble cluster. Journal of Hydraulic Engineering.

${ }^{89}$ Taylor, G. I. The spectrum of turbulence. Proceedings of the Royal Society of London A: 9athematical, Physical and Engineering Sciences, 1938. The Royal Society, 476-490.

${ }^{90} \mathrm{Nepf}, \mathrm{H} .1999$. Drag, turbulence, and diffusion in flow through emergent vegetation. Water Resources Research, 35, 479-489. 
${ }^{90}$ Naden, P., Rameshwaran, P., Mountford, O. \& Robertson, C. 2006. The influence of macrophyte growth, typical of eutrophic conditions, on river flow velocities and turbulence production. Hydrological Processes, 20, 3915-3938.

${ }^{92}$ Madsen, J. D., Chambers, P. A., James, W. F., Koch, E. W. \& Westlake, D. F. 2001. The interaction between water movement, sediment dynamics and submersed macrophytes. Hydrobiologia, 444, 71-84.

${ }^{93}$ Green, J. C. 2005. Velocity and turbulence distribution around lotic macrophytes. Aquatic Ecology, 39, 01-10.

${ }^{94}$ Sand-Jensen, K. \& Pedersen, O. 1999. Velocity gradients and turbulence around macrophyte stands in streams. Freshwater Biology, 42, 315-328.

${ }^{95}$ Siniscalchi, F., Nikora, V. I. \& Aberle, J. 2012. Plant patch hydrodynamics in streams: Mean flow, turbulence, and drag forces. Water Resources Research, 48, W01513.

${ }^{96}$ van Katwijk, M. M., Bos, A. R., Hermus, D. C. R. \& Suykerbuk W. 2010 Sediment modification by seagrass beds: muddification and sandification induced by plant cover and environmental conditions. Estuarine, Coastal and Shelf Science 89: 175-181.

${ }^{97}$ Statzner, B., Gore, J. A. \& Resh, V. H. 1988. Hydraulic stream ecology: observed patterns and potential applications. Journal of the North American Benthological Society, 7, 307-360.

${ }^{98}$ Hart, D. D., Clark, B. D. \& Jasentuliyana, A. 1996. Fine-scale field measurement of benthic flow environments inhabited by stream invertebrates. Limnology and Oceanography, 41, 297-308.

${ }^{99}$ Thomson, J., Clark, B., Fingerut, J. \& Hart, D. 2004. Local modification of benthic flow environments by suspension-feeding stream insects. Oecologia, 140, 533-542.

${ }^{100}$ Webb, P., Cotel, A. \& Meadows, L. 2010. Waves and eddies: effects on fish behavior and habitat distribution. Fish locomotion: an eco-ethological perspective. Science Publishers, Enfield, 1-39.

${ }^{101}$ Soluk, D. A. \& Craig, D. A. 1990. Digging with a vortex: flow manipulation facilitates prey capture by a predatory stream mayfly. Limnology and Oceanography, 35, 1201-1206.

${ }^{102}$ Quinn, J., Hickey, C. \& Linklater, W. 1996. Hydraulic influences on periphyton and benthic macroinvertebrates: simulating the effects of upstream bed roughness. Freshwater biology, 35, 301309.

${ }^{103}$ Robinson, C. A., Thom, T. J. \& Lucas, M. C. 2000. Ranging behaviour of a large freshwater invertebrate, the white-clawed crayfish Austropotamobius pallipes. Freshwater Biology, 44, 509-521.

${ }^{104}$ Brooks, A. J., Haeusler, T., Reinfelds, I. \& Williams, S. 2005. Hydraulic microhabitats and the distribution of macroinvertebrate assemblages in riffles. Freshwater Biology, 50, 331-344.

${ }^{105}$ Lancaster, J., Buffin-Belanger, T., Reid, I. \& Rice, S. 2006. Flow-and substratum-mediated movement by a stream insect. Freshwater Biology, 51, 1053-1069. 
${ }^{106}$ Rice, S. P., Buffin-Belanger, T., Lancaster, J. \& Reid, I. 2008. Movements of a macroinvertebrate species across a gravel-bed substrate: effects of local hydraulics and micro-topography under increasing discharge. IN: Habersack, H., Piegay, H. and Rinaldi M. (eds). Gravel-bed rivers VI: from process understanding to river restoration. Amsterdam ; London : Elsevier Science, pp. 637-660

${ }^{107}$ Webb, P. \& Cotel, A. 2010. Turbulence: does vorticity affect the structure and shape of body and fin propulsors? Integrative and comparative biology, 50, 1155-66.

${ }^{108}$ Ferner, M. C. \& Weissburg, M. J. 2005. Slow-moving predatory gastropods track prey odors in fast and turbulent flow. Journal of Experimental Biology, 208, 809-819.

${ }^{109}$ Liao, J. C. \& Cotel, A. 2013. Effects of turbulence on fish swimming in aquaculture. Swimming Physiology of Fish. Springer.

${ }^{110}$ Fenoglio, S., Boano, F., Bo, T., Revelli, R. \& Ridolfi, L. 2013. The impacts of increasing current velocity on the drift of Simulium monticola (Diptera: Simuliidae): a laboratory approach. Italian Journal of Zoology, 80, 443-448.

${ }^{111}$ Tonetto, A. F., Cardoso-Leite, R., Novaes, M. C. \& Guillermo-Ferreira, R. 2015. The relationship between macroalgal morphological complexity and hydraulic conditions in stream habitats. Hydrobiologia, 747, 33-41.

${ }^{112}$ Tonetto, A. F., Cardoso-Leite, R., Peres, C. K., Bispo, P. D. C. \& Branco, C. C. Z. 2014. The effects of habitat complexity and hydraulic conditions on the establishment of benthic stream macroalgae. Freshwater Biology, 59, 1687-1694.

${ }^{113}$ Maia, A. \& Wilga, C. 2016. Dorsal fin function in spiny dogfish during steady swimming. Journal of Zoology, 298, 139-149.

${ }^{114}$ Gazzola, M., Argentina, M. \& Mahadevan, L. 2014. Scaling macroscopic aquatic locomotion. Nature Physics, 10, 758-761.

${ }^{115}$ Blanckaert, K., Garcia, X. F., Ricardo, A. M., Chen, Q. \& Pusch, M. 2013. The role of turbulence in the hydraulic environment of benthic invertebrates. Ecohydrology, 6, 700-712.

${ }^{116}$ Hart, D. D. \& Fineli, C. M. 1999. Physical-biological coupling in streams: the pervasive effects of flow on benthic organisms. Annual Review of Ecology and Systematics, 363-395.

${ }^{117}$ Soluk, D. A. \& Craig, D. A. 1988. Vortex feeding from pits in the sand: A unique method of suspension feeding used by a stream invertebrate. Limnology and Oceanography, 33, 638-645.

${ }^{118}$ Shaw, E. 1978. Schooling fishes: the school, a truly egalitarian form of organization in which all members of the group are alike in influence, offers substantial benefits to its participants. American Scientist, 66, 166-175.

${ }^{119}$ Svendsen, J. C., Skov, J., Bildsoe, M. \& Steffensen, J. F. 2003. Intra-school positional preference and reduced tail beat frequency in trailing positions in schooling roach under experimental conditions. Journal of Fish Biology, 62, 834-846. 
${ }^{120}$ Munoz-Mas, R., Martinez-Caperl, F., Alcaraz-Hernandez, J. D. \& Mouton, A. 2015. Can multilayer perceptron ensembles model the ecological niche of freshwater fish species? Ecological Modelling, $309,72-81$.

${ }^{121}$ Fish, F. E. 2010. Swimming strategies for energy economy. Fish swimming: an etho-ecological perspective, 90-122.

${ }^{122}$ Asaeda, T. \& Rashid, M. 2016. Effects of turbulence motion on the growth and physiology of aquatic plants. Limnologica-Ecology and Management of Inland Waters.

${ }^{123}$ Odeh, M., Noreika, J., Haro, A., Maynard, A., Castro-Santos, T. \& Cada, G. 2002. Evaluation of the effects of turbulence on the behavior of migratory fish. Report prepared for U.S. Department of Energy, Bonneville Power Administration, \& Division of Fish and Wildlife, DOE/BP-00000022-1.

${ }^{124}$ Silva, A. T., Katopodis, C., Santos, J. M., Ferreira, M. T. \& Pinheiro, A. N. 2012. Cyprinid swimming behaviour in response to turbulent flow. Ecological Engineering, 44, 314-328.

${ }^{125}$ Deng, Z., Guensch, G. R., McKinstry, C. A., Mueller, R. P., Dauble, D. D. \& RICHMOND, M. C. 2005. Evaluation of fish-injury mechanisms during exposure to turbulent shear flow. Canadian Journal of Fisheries and Aquatic Sciences, 62, 1513-1522.

${ }^{126} \mathrm{Higham}$, T. E., Stewart, W. J. \& Wainwright, P. C. 2015. Turbulence, temperature, and turbidity: the ecomechanics of predator-prey interactions in fishes. Integrative and Comparative Biology, 55, 6-20.

${ }^{127}$ Havskum, H., Hansen, P. J. \& Berdlet, E. 2005. Effect of turbulence on sedimentation and net population growth of the dinoflagellate Ceratium tripos and interactions with its predator, Fragilidium subglobosum. Limnology and Oceanography, 50, 1543-1551.

${ }^{128}$ Joensuu, L., Pekcan-Hekim, Z., Hellen, N. \& Horpila, J. 2013. Turbulence disturbs vertical refuge use by Chaoborus flavicans larvae and increases their horizontal dispersion. Freshwater Biology, 58, 1997-2006.

${ }^{129}$ Rothschild, B. \& Osborn, T. 1988. Small-scale turbulence and plankton contact rates. Journal of Plankton Research, 10, 465-474.

${ }^{130}$ Cotel, A. J., Webb, P. W. \& Tritico, H. 2006. Do brown trout choose locations with reduced turbulence? Transactions of the American Fisheries Society, 135, 610-619.

${ }^{131}$ Silva, A. T., Santos, J. M., Ferreira, M. T., Pinheiro, A. N. \& Katopodis, C. 2011. Effects of water velocity and turbulence on the behaviour of Iberian barbel (Luciobarbus bocagei, Steindachner 1864) in an experimental pool-type fishway. River Research and Applications, 27, 360-373.

${ }^{132}$ Lamarre, H. \& Roy, A. G. 2005. Reach scale variability of turbulent flow characteristics in a gravelbed river. Geomorphology, 68, 95-113.

${ }^{133}$ Wilcox, A. C. \& Wohl, E. E. 2007. Field measurements of three-dimensional hydraulics in a steppool channel. Geomorphology, 83, 215-231. 
${ }^{134}$ MacVicar, B. \& Roy, A. 2007a. Hydrodynamics of a forced riffle pool in a gravel bed river: 1. Mean velocity and turbulence intensity. Water Resources Research, 43, W12401.

${ }^{135}$ Legleiter, C. J., Phelps, T. L. \& Wohl, E. E. 2007. Geostatistical analysis of the effects of stage and roughness on reach-scale spatial patterns of velocity and turbulence intensity. Geomorphology, 83, 322-345.

${ }^{136}$ David, G. C., Legleiter, C. J., Wohl, E. \& Yochum, S. E. 2013. Characterizing spatial variability in velocity and turbulence intensity using 3-D acoustic Doppler velocimeter data in a plane-bed reach of East St. Louis Creek, Colorado, USA. Geomorphology, 183, 28-44.

${ }^{137}$ Roy, M., Roy, A. \& Legendre, P. 2010. The relations between 'standard' fluvial habitat variables and turbulent flow at multiple scales in morphological units of a gravel-bed river. River Research and Applications, 26, 439-455.

${ }^{138}$ Tullos, D. \& Walter, C. 2015. Fish use of turbulence around wood in winter: physical experiments on hydraulic variability and habitat selection by juvenile coho salmon, Oncorhynchus kisutch.

Environmental Biology of Fishes, 98, 1339-1353.

${ }^{139}$ Baker, K., Chadwick, M. \& H., Sulaiman, Z. 2016. Eco-hydromorphic Classification for Understanding Stream Macroinvertebrate Biodiversity in Brunei Darussalam, Northern Borneo. Zoological Studies, 55.

${ }^{140}$ Perks, J. 2017. Filming freshwater fish (presentation). Institute of Fisheries Management Greater London and SE Branch Meeting, $1^{\text {st }}$ February 2017, Kings College London, London. 